\title{
RANCANG BANGUN SISTEM PEMANFAATAN PANAS BUANG PADA KOMPOR PORTABEL MENGGUNAKAN THERMOELECTRIC GENERATOR
}

\author{
Samuel Hans Jefferson ${ }^{1}$, Chairul Hudaya ${ }^{2 *}$ \\ 'Departemen Teknik Elektro, Fakultas Teknik Universitas Indonesia \\ Kampus Baru UI Depok 16424 Indonesia \\ ${ }^{2}$ Program Studi Magister Manajemen Inovasi, Sekolah Pascasarjana Universitas Teknologi Sumbawa \\ Jl. Olat Maras Raya, Batu Alang, Moyo Hulu, Sumbawa, Nusa Tenggara Barat Indonesia \\ *Corresponding Author email: c.hudaya@uts.ac.id
}

\begin{abstract}
Abstrak
Diterima:

Populasi dunia yang terus berkembang menyebabkan kebutuhan energi meningkat pesat.

Bulan Januari

2021

Pada kenyataannya belum semua daerah memiliki pasokan energi listrik khususnya daerah yang terletak di tempat terpencil dan sulit diakses. Selain itu menipisnya cadangan bahan bakar fosil sebagai sumber utama untuk membangkitkan listrik dan efek pencemaran yang buruk juga mendorong perubahan sumber energi menjadi energi baru

Diterbitkan: terbarukan (EBT). Tujuan dari penelitian ini adalah untuk merancang suatu solusi untuk

Bulan Februari mengatasi kedua hal tersebut dengan menggunakan sistem pemanfaatan panas buang 2021 (waste-heat recovery) pada pembakaran domestik khususnya kompor portabel. Thermoelectric generator (TEG) menjadi pilihan yang tepat karena memiliki beberapa kelebihan yang dibutuhkan seperti proses konversi yang sederhana, keandalan yang tinggi, dan kemudahan dalam penerapan. Penelitian akan membahas rancang bangun alat

Keyword :

Thermoelectric Generator (TEG), waste-heat recovery pada kompor portabel secara mekanik dan elektrik. Rancang bangun dilakukan terhadap 2 jenis modul TEG yang berbeda yaitu TEP1-1264-3.4 dan SP1848-

Kompor Portabel 27145. Alat yang diajukan memiliki perkiraan daya keluaran sekitar 9,24 W untuk modul TEP1-1264-3.4 dan 9,0048 W untuk modul SP1848-27145 dengan menggunakan 8 modul TEG dengan perkiraan perbedaan suhu sebesar $60^{\circ} \mathrm{C}$ dan sistem pendingin berbasis air. Dengan demikian modul TEP1-1264-3.4 menghasilkan daya yang lebih tinggi dibandingkan modul SP1848-27145 dan konfigurasi seri dinilai lebih baik karena tidak memiliki masalah ketika mengalami perbedaan tegangan antar modul. Rancang bangun mekanik yang dibuat memiliki 2 bagian rangka terpisah untuk memudahkan pemeliharaan rangkaian.
\end{abstract}

\section{PENDAHULUAN}

Perkembangan populasi dunia yang meningkat secara pesat menyebabkan kebutuhan energi dunia semakin bertambah. Hal ini bertolak belakang dengan penyusutan ketersediaan sumber energi yang paling banyak digunakan saat ini yaitu bahan bakar fosil. Tentunya perlu adanya sumber energi alternatif baru yang bisa disebut energi baru terbarukan (EBT). Sebagian besar konversi energi dilakukan dengan cara pembakaran termasuk kompor gas. Pada kenyataannya banyak sekali energi panas yang terbuang ketika melakukan pembakaran karena tidak semua panas yang dihasilkan api kompor digunakan untuk memasak.

Dalam menggunakan efisiensi pembakaran bahan bakar fosil, waste-heat recovery menjadi salah satu jawaban atas masalah tersebut. Pada penerapan rumah tangga khususnya kompor gas, waste-heat recovery berbasis thermoelectric generator (TEG) menjadi salah satu pilihan yang terbaik untuk diterapkan karena memiliki beberapa kelebihan yang cocok untuk digunakan dalam kegiatan rumah tangga khususnya penggunaan kompor gas (LPG).

Pada jarak tertentu dari samping kompor gas, suhu yang dihasilkan dapat mencapai $100^{\circ} \mathrm{C}$ $150^{\circ} \mathrm{C}$ jika pengukuran tanpa adanya rugi-rugi dari konduktivitas panas dan bergantung pada diameter firewall dari kompor (R. R. V. Sona, 2012). Jika dibandingkan dengan suhu ruangan menurut SATP adalah $25^{\circ} \mathrm{C}$ (STP, 2020) diharapkan nilai perbedaan suhu mencapai $60^{\circ} \mathrm{C}$. Dengan demikian nilai output rating dapat diperkirakan menjadi $9 \mathrm{~W}$.

Tujuan dilakukannya penelitian ini adalah untuk membuat sebuah generator listrik yang dapat memanfaatkan panas yang terbuang dari kompor portabel sebagai sumber energinya. Hal ini sangat memungkinkan jika ditinjau dari potensi perbedaan suhu dan kebutuhan daya yang diinginkan.

\section{LANDASAN TEORI}

\section{Waste-Heat Recovery}

Waste-heat merupakan sebuah energi yang dihasilkan dari proses yang menghasilkan usaha sehingga energi tersebut terbuang ke lingkungan 
sekitar (H. Jouhara, 2018). Diperkirakan bahwa 20$50 \%$ konsumsi energi pada industri terbuang menjadi panas (I. Johnson, 2008). Hal inilah yang menyebabkan proses waste-heat recovery memiliki potensi yang cukup besar untuk dikembangkan. Penerapan waste-heat recovery tidak hanya terpaku dalam skala industry saja namun bisa diterapkan pada skala yang lebih kecil seperti rumah tangga, otomotif, dll. Dengan berbagai metode yang ada, waste heat recovery tidak terpaku pada tempat dan skala penerapan sehingga potensi waste heat dapat digunakan secara optimal pada berbagai macam bidang.

Penggunaan waste heat recovery untuk menghasilkan listrik juga sangat baik untuk digunakan di daerah yang masih belum terhubung dengan jaringan listrik. Sehingga dengan memanfaatkan waste-heat recovery di bidang domestik, penduduk di daerah tersebut dapat menggunakan listrik setidaknya untuk penerangan sekaligus meningkatkan efisiensi dari proses pembakaran yang digunakan masyarakat.

\section{Thermoelectric Generator}

\section{Thermoelectric}

generator (TEG)

merupakan sebuah alat yang bekerja berdasarkan efek seebeck yang secara umum digunakan untuk mengubah energi panas menjadi energi listrik (D. Champier, 2017). TEG sendiri memiliki berbagai jenis konstruksi bergantung pada tujuan penggunaaan modul. TEG terdiri dari beberapa modul thermoelectric yang dimasukkan di antara dua heat exchanger.

TEG memiliki beberapa kelebihan untuk digunakan seperti:

(1). Konversi energi panas menjadi energi listrik secara langsung sehingga tidak membutuhkan tahapan yang banyak dalam proses konversi.

(2). Perangkat solid-state sehingga tidak memiliki komponen yang bergerak sehingga dapat mengurangi biaya perawatan dan umur pakai yang lebih lama.

(3). Dapat digunakan dalam skala apapun mulai dari industrial, antariksa, otomotif, bahkan skala domestik.

(4). Memungkinkan untuk digunakan pada posisi apapun.

Untuk waktu yang lama, modul yang tersedia untuk aplikasi industri dengan harga yang terjangkau hanya modul Bismuth Telluride. Modul ini memiliki nilai ZT sekitar 1 pada temperature $50^{\circ} \mathrm{C}$ dan semakin berkurang pada pada temperature yang lebih tinggi. Temperatur maksimum modul tersebut untuk bekerja ada pada sekitar $200^{\circ} \mathrm{C}$ sampai $300^{\circ} \mathrm{C}$ bergantung pada produsen modul tersebut. Namun kelangkaan material Bismuth dan Tellurium pada kerak bumi menghambat perkembangan lebih jauh dari TEG dengan bahan dasar Bismuth Telluride (USGS, 2020). Hal ini mendorong beberapa pabrikan untuk melakukan riset dan pengembangan terkait material $\mathrm{TE}$ sehingga didapatkan beberapa material yang ada saat ini sebagai berikut,

Ada beberapa faktor yang dibutuhkan dari penggunaan TE untuk membuat sebuah generator yang kuat yaitu:

(1). Penukar panas untuk memperkuat transfer kalor antara modul dan sumber panas.

(2). Konverter elektrik untuk mengubah level tegangan yang sesuai dengan alat penyimpan daya seperti baterai dan kapasitor.

Efisiensi sistem secara keseluruhan dapat diartikan sebagai perbandingan antara energi yang tersimpan atau disediakan untuk pengguna dengan energi yang dikonsumsi. Energi yang dikonsumsi sebagian besar dikumpulkan pada sisi panas, namun bisa juga termasuk energi mekanik yang diperlukan untuk menjalankan sistem, seperti sistem pendingin pada heat sink sisi dingin. Sehingga efisiensi sistem meliputi efisiensi dari penukar panas, efisiensi modul TE, efisiensi konverter, dan kemampuan untuk mengoptimasi beban listrik (D. Champier, 2017).

Performa dari modul TE sangat rendah, sehingga desain generator membutuhkan pendekatan sistem untuk mengoptimasi sistem secara keselurahan seperti:

(1). Riset pada material thermoelectric untuk mendapatkan nilai ZT setinggi mungkin.

(2). Studi pada penukar panas dan coupling dengan modul TE.

(3). Studi pada konverter dan rangkaian listrik dari modul agar output dapat sesuai dengan spesifikasi yang diinginkan.

(4). Studi numerik untuk optimasi generator dengan mempertimbangkan berbagai hal seperti geometri modul dan variasi sifat material berdasarkan temperatur.

Sebuah generator TE terdiri dari beberapa pasangan semikonduktor $\mathrm{p}$ dan $\mathrm{n}$, semikonduktor tersebut terhubung seri secara elektris dan terhubung parallel secara termal yang dapat dilihat pada gambar 2-3 (S. Siouane, 2017). Dari konstruksi tersebut dapat diamati bahwa TEG tidak memiliki komponen bergerak sehingga meningkatkan keandalan secara signifikan. 


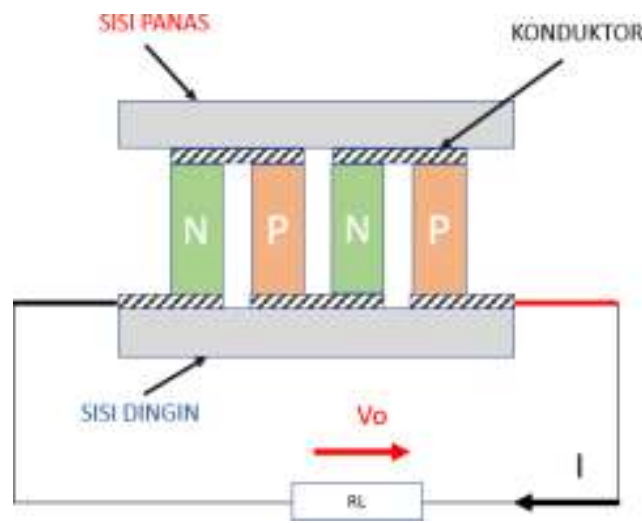

Gambar 1 Struktur TEG

Ada 3 parameter utama yang menggambarkan sebuah TEG sebagai berikut,

(1). Koefisien seebeck $\alpha$ yang bergantung pada material TE yang digunakan untuk membuat semikonduktor p-n.

(2). Resistansi elektris dari semikonduktor p-n dan dan koneksi yang digunakan untuk menghubungkan TEG dengan beban listrik.

(3). Resistansi termal dan koneksi yang digunakan untuk menghubungkan TEG kepada sumber energi panas yang diperlukan.

\section{METODE PENELITIAN}

Metodologi yang digunakan dalam rancang bangun tersebut adalah dengan mengumpulkan data dan informasi yang terkait dengan rancang bangun tersebut baik melalui buku, jurnal, dan internet. Rancang bangun dilakukan dengan mempertimbangkan data dan informasi yang didapat serta saran dari pembimbing melalui bimbinganbimbingan yang dilakukan. Dimensi alat disesuaikan dengan hasil pengukuran kompor portabel yang digunakan.

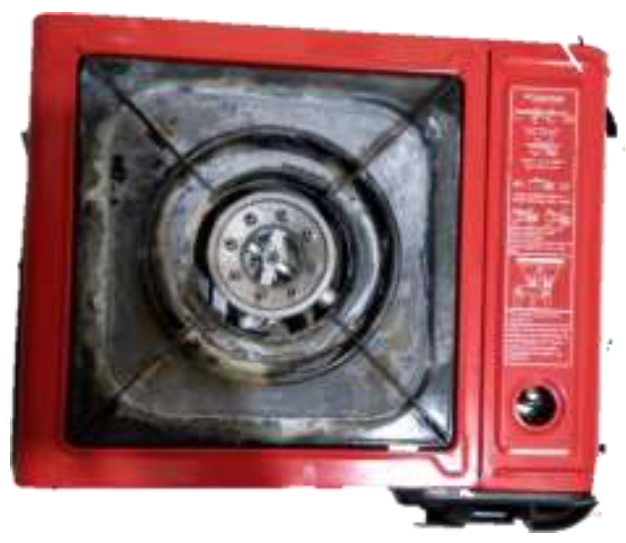

Gambar 2 Kompor Portabel

Rancang bangun mekanik dilakukan menggunakan perangkat lunak Autodesk Inventor di mana dimensi dari rancang bangun alat tersebut sudah disesuaikan dengan kompor yang terterapada gambar. Perkiraan daya keluaran dilakukan berdasarkan spesifikasi modul dengan menggunakan persamaan KVL dan KCL sebagai berikut,

$$
\begin{aligned}
& \sum V_{\text {total }}=V_{1}+V_{2}+\cdots+V_{n} \\
& \sum I_{\text {in }}=\sum I_{\text {out }}
\end{aligned}
$$

Sehingga dengan mengetahui nilai tegangan dan arus total didapatkan daya dengan menggunakan persamaan berikut,

$$
P=V \times I
$$

\section{HASIL DAN PEMBAHASAN}

\section{Rancangan Elektrik}

Pada rancangan elektronik alat pada seminar ini adalah menggunakan 8 modul TEG dengan mempertimbangkan konfigurasi dan 2 jenis modul TEG yaitu SP1848-27145 dan TEP1-12643.4 yang memiliki perbedaan spesifikasi.

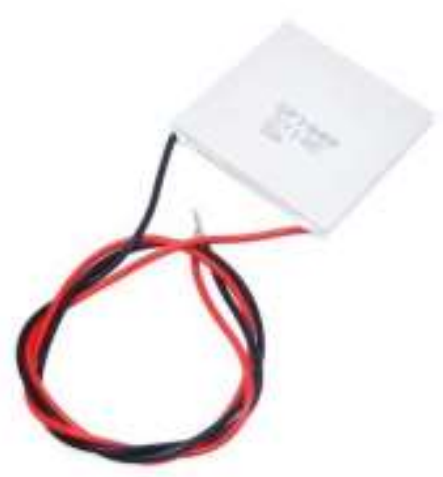

Gambar Error! No text of specified style in document. SP1848-27145

Yang pertama adalah modul TE SP184827145 yang merupakan modul yang umum dijual di pasaran dan sangat terjangkau. Spesifikasi dari modul SP1848-27145 dapat dilihat sebagai berikut,

TABEL 1 SPESIFIKASI SP1848-27145

\begin{tabular}{cc}
\hline Modul Termoelektrik SP1848-27145 \\
\hline Size & $40 \mathrm{~mm}$ x $40 \mathrm{~mm}$ x 4
\end{tabular}

\begin{tabular}{|c|c|}
\hline & Operasi \\
\hline Perbedaan Suhu $\left({ }^{\circ} \mathrm{C}\right)$ & \\
\hline $\begin{array}{l}\text { Tegangan Keluaran } \\
\text { Hubung Terbuka (V) }\end{array}$ & \\
\hline $\begin{array}{l}\text { Arus Keluaran Hubung } \\
\text { Singkat (mA) }\end{array}$ & \\
\hline
\end{tabular}

Suhu Operasi

$\mathrm{mm}$

Dapat dilihat pada tabel bahwa suhu operasi tersebut sangat dekat dengan suhu sumber panas yaitu kompor di mana suhu operasi kompor berkisar $100^{\circ} \mathrm{C}-150^{\circ} \mathrm{C}$. 


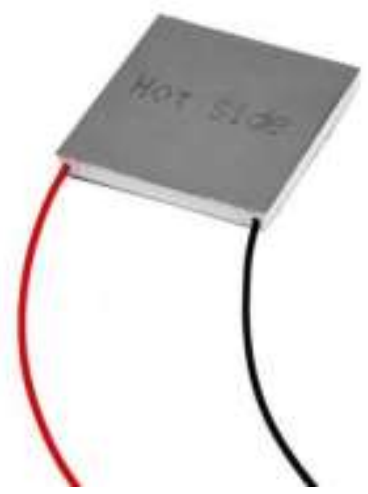

Gambar 4 TEP1-1264-3.4

Pertimbangan kedua adalah modul TEP11264-3.4, namun modul ini memiliki kendala dalam hal ketersediaan. Spesifikasi modul TEP1-1264-3.4 dapat dilihat sebagai berikut,

TABEL 2 SPESIFIKASI TEP1-1264-3.4 Modul Termoelektrik TEP1-1264-3.4

Dimensi

Suhu Operasi

Perbedaan Suhu

$\left({ }^{\circ} \mathrm{C}\right)$ $40 \mathrm{~mm}$ x $40 \mathrm{~mm}$ x $4 \mathrm{~mm}$ Operasi $30^{\circ} \mathrm{C}$ to $+300^{\circ} \mathrm{C}$

Tegangan Keluaran

Hubung Terbuka

(V)

Arus Keluaran

Hubung Singkat

(mA)

TEP1-1264-3.4 memiliki spesifikasi suhu operasi yang lebih baik dan jauh di atas suhu operasi kompor yang akan digunakan menyebabkan modul tersebut lebih aman untuk digunakan.

\section{Konfigurasi Seri}

Konfigurasi seri digunakan untuk menghasilkan tegangan yang tinggi. Konfigurasi seri dapat membantu untuk menaikkan tegangan dari keluaran modul TE sehingga dapat memenuhi spesifikasi yang diinginkan namun tetap membutuhkan step down converter untuk menurunkan level tegangan.

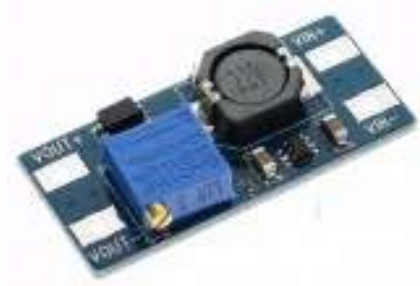

Gambar 5 MT3608

TABEL 3 SPESIFIKASI MT3608 MT3608

\begin{tabular}{|c|c|}
\hline $\begin{array}{l}\text { Arus Keluaran } \\
\text { Maksimum }\end{array}$ & $2 \mathrm{~A}$ \\
\hline Tegangan & $2-24 \mathrm{~V}$ \\
\hline $\begin{array}{l}\text { Tegangan } \\
\text { Keluaran }\end{array}$ & $5 \mathrm{~V}$ \\
\hline $\begin{array}{l}\text { Efisiensi } \\
\text { Dimensi }\end{array}$ & $\begin{array}{c}>93 \% \\
37,211 \times 17,272 \times 6 \mathrm{~mm}\end{array}$ \\
\hline
\end{tabular}

Rancangan kali ini menggunakan 8 modul sehingga perhitungan tegangan berdasarkan data untuk modul SP1848-27145 akan menghasilkan $8 \mathrm{x}$ $2,4 \mathrm{~V}$ yang berarti total tegangan output menjadi 19,2 V, arus keluaran menjadi 0,469 A, dan daya keluaran 9,0048 W. Untuk modul TEP1-1264-3.4 akan menhasilkan tegangan $8 \times 3,3 \mathrm{~V}$ sehingga tegangan total menjadi $26,4 \mathrm{~V}$ dan arus menjadi 0,35 A, dan daya keluaran 9,24 W. Untuk keluaran dari konverter belum dapat diestimasi karena membutuhkan pengukuran data lebih lanjut.

\section{Konfigurasi Paralel}

Konfigurasi paralel digunakan untuk menghasilkan arus yang tinggi menurut hukum arus Kirchoff. arus dari rangkaian paralel akan sama dengan akumulasi arus setiap modul. Tegangan keluaran dari konfigurasi paralel sangat rendah maka diperlukan step-up converter untuk menaikkan nilai tegangan. Namun penggunaan rangkaian parallel tidak disarankan akibat perbedaan tegangan tiap modul dapat menimbulkan rugi-rugi.

Untuk modul SP1848-27145 akan menghasilkan $8 \times 0,469$ A yang berarti total arus output menjadi 3,752 A, tegangan output menjadi $2,4 \mathrm{~V}$, dan daya keluaran 9,0048 $\mathrm{W}$. Untuk modul TEP1-1264-3.4 akan menhasilkan tegangan 8 x 0,35 A sehingga arus total menjadi 2,8 A dan tegangan menjadi 3,3 V, dan daya keluaran 9,24 W. Untuk keluaran dari konverter belum dapat diestimasi karena membutuhkan pengukuran data lebih lanjut.

\section{Hasil Perkiraan Spesifikasi}

Perkiraan spesifikasi yang didapat dari kedua jenis modul berdasarkan spesifikasi masingmasing modul dengan perbedaan suhu $60^{\circ} \mathrm{C}$.

TABEL 4 PERBANDINGAN PERKIRAAN PERFORMA MENGGUNAKAN SP1848-27145 DAN TEP1-1264-3.4

\begin{tabular}{lllll}
\hline SPESIFIKASI & \multicolumn{2}{l}{ SP1848-27145 } & \multicolumn{2}{l}{ TEP1-1264-3.4 } \\
& & & & \\
\hline Konfigurasi & Seri & Paralel & Seri & Paralel \\
& & & & \\
Tegangan & $19,2 \mathrm{~V}$ & $2,4 \mathrm{~V}$ & 26,4 & $3,3 \mathrm{~V}$ \\
$\begin{array}{l}\text { Keluaran Hubung } \\
\text { Terbuka }\end{array}$ & & & $\mathrm{V}$ & \\
& & & & \\
$\begin{array}{l}\text { Arus Keluaran } \\
\text { Hubung Singkat }\end{array}$ & $\mathrm{A}$ & & & \\
\end{tabular}




$\begin{array}{lllll}\text { Estimasi Daya } & 9,0048 & 9,0048 & 9,24 & 9,24 \mathrm{~W} \\ \text { Keluaran } & \text { W } & \text { W } & \text { W } & \end{array}$

Dari tabel tersebut dapat dilihat bahwa TEP1-1264-3.4 menghasilkan perkiraan daya yang lebih besar yaitu 9,24 W.

\section{Rancangan Mekanik}

Rancang bangun mekanik yang diajukan terdiri dari 2 rangka yang terdiri dari rangka utama dan rangka dinding TEG.

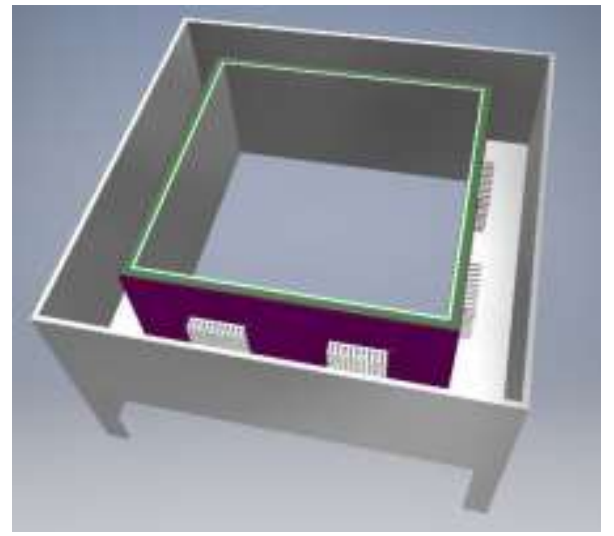

Gambar 6 Struktur Rancang Bangun Alat Keseluruhan

Untuk rangka utama bagian dalam berfungsi sebagai penukar panas yang langsung menghantarkan panas dari sumber. Hal inilah yang membuat material terpilih harus memenuhi ketahanan terhadap panas namun tetap dapat berfungsi sebagai penghantar panas yang baik. Selain itu rangka juga digunakan untukmenampung air sehingga perlu material yang kedap air dan tahan terhadap korosi.

Modul TE diletakkan pada rangka yang terpisah dari rangka utama. Hal ini disebabkan agar modul TEG dapat dilepas untuk memudahkan pemeliharan dan pengembangan dari rangkaian. Rangka tersebut memiliki lubang yang ukurannya sudah disesuaikan dengan modul TE yang digunakan. Lubang tersebut digunakan sebagai peletakkan heatsink serta modul TE. Setiap lubang yang ada akan dipasang heatsink yang ukurannya telah disesuaikan. Heatsink yang digunakan memiliki guratan secara vertical dan horizontal yang akan memaksimalkan luas permukaan untuk pelepasan panas yang lebih cepat. Material heatsink yang dipilih adalah alumunium yang memiliki konduktivitas panas yang baik. Modul TEG akan ditempel pada heatsink menggunakan thermal paste untuk mempercepat perpindahan panas agar suhu pada sisi dingin tetap terjaga.

Busa digunakan sebagai pelapis dalam rangka TEG untuk mencegah kontak langsung dan mengisolasi panas dari konduktor pada sisi dalam rangka utama. Penggunaan busa tersebut ditujukan untuk menjaga suhu air dan sisi dingin TEG agar tetap stabil atau mempertahankan suhunya.

Selanjutnya rangka TEG akan dipasang pada rangka utama sehingga menjadi suatu kesatuan yang utuh. Setelah semuanya sudah terpasang, rangka utama akan diisi air sebagai pendingin agar perbedaan suhu dapat terjaga dan daya yang dihasilkan menjadi stabil dan modul TEG dapat menghasilkan energi listrik untuk waktu yang lebih lama.

\section{PENUTUP}

\section{Kesimpulan}

Implementasi penggunaan TEG memiliki tantangan tersendiri dalam memaksimalkan pertukaran panas baik penyerapan maupun pelepasan panas itu sendiri. Hal tersebut diakibatkan oleh prinsip kerja TEG yang mengandalkan perbedaan suhu antara kedua sisi untuk menghasilkan energi listrik. Dengan demikian perbedaan suhu antara kedua sisi harus dijaga untuk tetap stabil. Rancang bangun yang telah diajukan sudah dirancang menurut perhitungan, pertimbangan sifat mekanis, dan pemilihan material yang sesuai dengan kegunaannya masing-masing. Rancang bangun alat tersebut menggunakan sistem pendingin berbasis air untuk menjaga perbedaan suhu antara kedua sisi modul TEG sehingga diharapkan alat dapat terus menghasilkan listrik dalam waktu yang lama. Pada rancang bangun tersebut digunakan perbandingan 2 jenis modul TEG yaitu dengan menggunakan masing-masing 8 modul SP1848-27145 dan TEP1-1264-3.4. Kedua modul dapat menghasilkan daya sekitar $9 \mathrm{~W}$ pada perbedaan suhu $60^{\circ} \mathrm{C}$. Modul TEP1-1264-3.4 mampu menghasilkan daya yang lebih tinggi yaitu 9,24 W dibandingkan modul SP1848-27145 yang hanya mampu menghasilkan 9,0048 W. Sehingga daya keluaran sudah memenuhi spesifikasi yang diinginkan. Namun penggunaan konfigurasi paralel tidak dianjurkan karena perbedaan tegangan antar modul dapat menyebabkan kerugian. Nilai tegangan dan arus akhir belum dapat ditentukan karena hasil keluaran dari konverter yang membutuhkan pengujian dan pengambilan data lebih lanjut sehingga data tersebut masih dapat berubah akibat faktor-faktor yang mungkin ditemukan saat pengujian.

\section{REFERENSI}

R. R. V. Sona, S. Soetadi, and S. Kawano, "Studi Eksperimen Distribusi Temperatur Nyala Api Kompor Bioetanol Tipe Side Burner dengan Variasi Diameter Firewall," vol. 1, pp. 1-5, 2012. 
H. Jouhara, N. Khordehgah, S. Almahmoud, B. Delpech, A. Chauhan, and S. A. Tassou, "Waste heat recovery technologies and applications," Termal Science and Engineering Progress, vol. 6. Elsevier Ltd, pp. 268-289, 01-Jun-2018, doi: 10.1016/j.tsep.2018.04.017.

I. Johnson, W. T. Choate, and A. Davidson, "Waste Heat Recovery. Technology and Opportunities in U.S. Industry,” Mar. 2008.

D. Champier, "Thermoelectric generators: A review of applications," Energy Conversion and Management, vol. 140. Elsevier Ltd, pp. 167-181, 15-May-2017, doi: 10.1016/j.enconman.2017.02.070.

S. Siouane, S. Jovanović, and P. Poure, "Equivalent Electrical Circuits of Thermoelectric
Generators under Different Operating Conditions," Energies, vol. 10, no. 3, p. 386, Mar. 2017, doi: 10.3390/en10030386.

\section{Internet}

Engineeringtoolbox. 2020. STP - Standard Temperature and Pressure \& NTP - Normal Temperature and Pressure. https://www.engineeringtoolbox.com/stpstandard-ntp-normal-air-d_772.html. Diunduh pada 16 Desember 2020.

USGS. 2020. Rare Earth Elements-Critical Resources for High Technology | USGS Fact Sheet 087-02.

https://pubs.usgs.gov/fs/2002/fs087-02/. Diunduh pada 15 Desember 2020. 